\title{
INNOVATION, RISK AND UNCERTAINTY: A STUDY OF TOURISM ENTREPRENEURS
}

\author{
(Forthcoming in Journal of Travel Research)
}

\author{
Allan M. Williams \\ School of Hospitality and Tourism Management \\ Faculty of Arts and Social Sciences \\ University of Surrey \\ Guildford GU2 7XH \\ E-mail: allan.williams@ surrey.ac.uk \\ Isabel Rodríguez Sánchez \\ School of Hospitality and Tourism Management \\ Faculty of Arts and Social Sciences \\ University of Surrey \\ Guildford GU2 7XH \\ E-mail: isabel.rodriguez@surrey.ac.uk \\ Vlatka Škokić \\ Faculty of Economics \\ University of Split \\ 21000 Split \\ Croatia \\ E-mail: vlatka.skokic@efst.hr
}

This research has been supported by the European Union Horizon 2020 Research and Innovation programme [grant agreement 700893]. 


\section{INNOVATION, RISK AND UNCERTAINTY: A STUDY OF TOURISM ENTREPRENEURS}

Innovation is inherently associated with risk and uncertainty, and the engagement of entrepreneurs with these is central to the innovation process. Entrepreneurs are not passive actors but, through learning, they contribute to the dynamic capabilities of the firm across the innovation process. Drawing on 57 interviews with entrepreneurs in tourism SMEs in Spain and the UK, the paper identifies how risk and uncertainty are understood to change throughout the innovation process in the key areas of technology, finance, markets and organizations. It also examines how tourism entrepreneurs respond to risk and uncertainty through a range of strategies, especially the harvesting of knowledge and networking. However, engaging with uncertainty remains elusive and relies as much on intuition as on reasoning.

\section{Keywords}

Uncertainty, risk, innovation process, tourism entrepreneurs, learning, risk and uncertainty management. 


\section{Introduction}

Innovation is inherently associated with risk and uncertainty. Moreover, greater competition, rapidly changing technology and customer expectations increasingly make innovation more complex with less predictable outcomes (Keizer, Vos, and Halman 2005), intensifying the innovator's exposure to risk and uncertainty (Berglund 2007). As Janeway (2012, 58-9) comments: "The innovation economy... is saturated in unquantifiable uncertainty". The role of the entrepreneur in relation to uncertainty has long been contested, with Schumpeter (1934) considering it is to manage these conditions, whereas Knight (1921) argued that uncertainty was the driver of innovation diffusion. Although there is a broad consensus in the extant literature around Knight's perspective, risks and uncertainties do create a role for the entrepreneur who has to manage these (Van Gelderen, Frese, and Thurik 2000).

During the innovation process (Schroeder, Van de Ven, Scudder, and Polley 1986), entrepreneurs face a range of risks (known risks) and uncertainties (unknown risks). Risks tend to be conceptualised in terms of costs (March and Shapira 1987) whereas most entrepreneurial decisions have to be made under conditions of uncertainty (Jalonen 2012). Entrepreneurs are not passive actors. Rather, the innovation process largely depends on the entrepreneur's capacity to manage variable levels of risk and uncertainty. Specifically it depends on the dynamic capabilities of the entrepreneurs, and enterprises (Teece, Peteraf, and Leih 2016), which are informed by learning and accumulated experience during the innovation process.

There is a growing body of literature on the role of risk and uncertainty in the innovation process (see Jalonen's 2012 review). However, this is largely quantitative, and fails to explore either the shifting and blurred meanings and understanding of risks, or the dynamic capabilities of entrepreneurs which evolve across the different stages of the innovation process. The existing literature also tends to treat risk and uncertainty as synonymous 
(Alvarez and Barney 2005), leading Liesch, Welch, and Buckley (2011) to call for a more nuanced approach.

The above research gaps on risk and uncertainty in the generic innovation literature are amplified in the tourism literature, partly reflecting the general selectivity and rather belated emergence of substantial empirical research on innovation in tourism SMEs (Thomas, Shaw, and Page 2011). There is also a significant body of research on generic tourism entrepreneurship (Fu, Okumus, Wu and Köseoglu 2019; Thomas et al. 2011), yet with virtually no significant engagement with innovation, risk and uncertainty. For tourism entrepreneurs, these issues are of crucial importance and require further examination as: 1) small firms dominate the tourism industry, which are on the one hand a hotbed of innovative practices and on the other hand have limited resources and therefore are especially vulnerable to uncertainty and risk (Verreynne et al. 2019; Power, Di Domenico and Miller, 2019); 2) there is evidence that industrial dynamics and industry effects can significantly influence the level of risk and uncertainty and entrepreneurial behavior (Shepherd 2015), but research on tourism innovation is still relatively thin; 3) tourism entrepreneurs operate in highly contested markets which increase uncertainties (Verreynne et al. 2019) and they are vulnerable to external shocks in major markets or the supply chain (Ritchie 2004); 4) the temporality of demand is an important determinant of firm performance (Park, et al. 2016) and therefore likely to be a focus of innovation among tourism firms; 5) a significant number of tourism entrepreneurs, often described as "lifestyle entrepreneurs", create innovative products and serve niche markets (Ateljevic and Doorne 2000), which together with the strong intertwining of market uncertainty and firm-specific uncertainty (Aarstad, Ness, and Haughland 2015), has significant influence on the risk and uncertainty they face. The roles of risk and uncertainty in tourism entrepreneurship and innovation have been recognised at the conceptual level (Hall and Williams 2008; Williams and Baláž 2014). There have also been 
extensive empirical studies of the role of risks and uncertainty in tourists ' willingness to take risk (Williams and Baláž 2013). However, there have been few, and mostly partial, empirical studies of how uncertainty and risk explicitly relate to the tourism innovation process: for example, Decelle (2004) has considered the risks associated with what he terms 'difficulties' in tourism innovations, and Aarstad et al. (2015) analyse uncertainty as a catalyst in networking. Only Verreynne et al. (2019) have explicitly addressed the role of uncertainty in tourism innovation, analyzing how it mediates the relationship between innovation diversity and firm performance. However, they provide no insights into the roles of different forms of risk and uncertainty across the different stages of the innovation process, which instead is treated as a single event rather than a process.

In response to the limited explicit research on risk and uncertainty in both the generic and the tourism innovation literature, this paper provides an original and monographic view of how they change across the stages of the innovation process. A qualitative approach is adopted which draws on 57 in-depth interviews with tourism entrepreneurs in Spain and the UK to address two research questions:

1. How do tourism entrepreneurs understand risks and uncertainties across the different stages of the innovation process?

2. How do tourism entrepreneurs manage risks and uncertainties across these stages?

The paper's contribution lies in developing and exploring an interpretative framework of the changing interplay of different types of risks and uncertainties that can impact throughout the tourism innovation process. It is also the first substantial empirical study which explicitly analyses in detail how both risks and uncertainties are understood by entrepreneurs across the innovation processes and how they address these in context of their dynamic capacities. 
First, a literature review is presented to provide a conceptual framework of the key issues which will be explored empirically such as risk and uncertainty, types of risks and uncertainties along the stages of the innovation process, and strategies to manage these. This is followed by an outline of the research methods while the last two sections present the analysis of the perceived risks and their management, followed by a discussion and the conclusions of the study.

\section{Theoretical Review}

The role of risk and uncertainty is an important focus of the research on both entrepreneurship and innovation, and is rooted in the contrasts between the approaches of Schumpeter and Knight (Brouwer 2000). Schumpteter's (1934) earlier work considered that the function of the entrepreneur was to manage risk and uncertainty during the innovation process, and to constitute a pioneer who can 'act with confidence beyond the range of familiar beacons' (Schumpeter 1942, 132). Although Schumpeter is contradictory about whether entrepreneurs are risk takers (Kanbur 1980), he views risk and uncertainty as obstacles to innovation, which have to be managed. In contrast, Knight (1921) views uncertainty as a driver of innovation diffusion because it creates the opportunity for profit which would only be temporary if change was predictable (Brouwer 2000); in other words, uncertainty is a precondition for entrepreneurship. Over time, there has been broad consensus that uncertainty creates need, and opportunities, for innovation (Freel 2005), and that 'the entrepreneur functions in the economy only if the environment is uncertain'.

Looking beyond this debate, then 'since uncertainty is a fact of economic life, entrepreneurs are needed for arbitrage, to take risks and to innovate' (Van Gelderen et al. 2000, 169). Therefore, the entrepreneur is the bearer of the uncertainties inherent in investing time, effort 
and financial resources in the expectation of uncertain and uninsurable returns (Venkataraman 1997, 124). Indeed, there is 'general agreement that risk bearing is a necessary prerequisite for being called an entrepreneur' (Wärneryd 1988, 407).

This has led to research on whether entrepreneurs are more willing to engage with risks and uncertainty. For example, Johnson (2001) considers that 'things happen' only when individuals are able to engage with uncertainty and ambiguity. There is some evidence that entrepreneurs are more risk tolerant (Gifford 2003; Stewart et al. 1999). However, arguably there is more evidence that they are not knowingly more risk tolerant but rather are more likely to have 'overconfidence, the illusion of control, and be prepared to draw conclusions from limited knowledge' (Simon, Houghton, and Aquino 2005, 113). Risk tolerance is usually measured using complex constructs and is quantitatively analysed, whereas this paper relies on qualitative methods, and therefore it is not investigated here. Instead, we consider entrepreneurs' nuanced understanding of risk and uncertainty. A second strand of literature considers the differential abilities of entrepreneurs to deal with risk and uncertainty (Venkataraman 1997, 130), and how they respond to these is critically important.

A significant portion of the tourism entrepreneurship literature has been preoccupied with the dichotomy between 'lifestyle' and 'growth-oriented' tourism entrepreneurs where entrepreneurial attitudes towards risk were often used as a distinguishing factor among the two groups (Thomas et al. 2011). The former are more concerned about improving their quality of life rather than growing their businesses and very often reject business growth just to reduce risk (Ioannides and Petersen 2003) while the latter are more likely to innovate, take risks and grow their firms. These studies were mostly concerned with the 'persons' aspects (e.g. startup motivation) and the characteristics of the environments where entrepreneurs operated (Fu et al. 2019) and did not examine directly their innovative practices and related risks and uncertainties. However, there were a few isolated attempts to demonstrate that even 
lifestyle entrepreneurs may face significant risks. For instance, their focus on niche markets is subject to rapid imitation especially from (large) businesses which are highly integrated, have more resources and can quickly replicate (Ateljevic and Doorne 2000) what are relatively easily observed innovations in tourism (Hall and Williams 2008). A study by Bosworth and Farrell (2011) shows that the survival of the business is one of the most significant lifetime risks they take, as their businesses become integral part of their lives and their families. In a different context, Skokic, Lynch and Morrison (2016) focused on a transitional setting of a former socialist economy and demonstrated that tourism entrepreneurs identified and responded to the lucrative niche markets which a turbulent (uncertain) environment offered, becoming more creative and able to engage with uncertainty and risk in their endeavors. However, so far there has been no attempt to understand how tourism entrepreneurs understand and manage risk and uncertainty, despite their crucial role in new product development, creation of niche markets and diversified destination development (Fu et al. 2019).

As noted in the introduction, our starting point is the lack of explicit analysis, even in the generic literature, of the role of risk and uncertainty across the innovation process, and how entrepreneurs understand and seek to manage it. There is even less - virtually no - explicit research on risk and uncertainty in the entrepreneurial and innovatory processes in tourism as described in Rodriguez, Williams, and Brotons (2017). Before proceeding further in considering how entrepreneurs respond to risk and uncertainty, we consider these terms in more detail. 


\section{Conceptualising risk and uncertainty}

Alvarez and Barney $(2005,778)$ consider that, in the entrepreneurship literature, 'risk and uncertainty are treated as if they were synonymous'. This leads Leisch, Welch, and Buckley (2011) to emphasise the need for a more nuanced understanding of whether and how entrepreneurs differentiate risk from uncertainty. Knight (1921) is associated with the classic differentiation between risk (known risks), and uncertainty (unknown risks). He also argues that risks, unlike uncertainty, are essentially insurable (Brouwer 2000). Hence, as March and Shapira $(1987,1411)$ emphasise, risk increasingly is seen in terms of costs rather than the unpredictability of outcomes. This can be in the form of the costs of insurance, although it may also involve other costs such as increased stockholding, hiring specialist labour, etc.

Although entrepreneurs have to manage these risks, they also have to engage with uncertainty. For Liesch, Welch, and Buckley (2011), Knightian uncertainty requires decisions to be made with limited or no knowledge (Buckley and Carter 2004, 372). Moreover, uncertainty is prevalent: Keynes (1937) considers it is akin to not knowing the rules of the game (Perminova, Gustafsson and Wikstrom 2008). The same point emerges from Jalonen's $(2012,2)$ review: 'Due to a lack of comprehensive, unambiguous, consistent and stable set of values, to a lack of perfect and complete information, and to constraints imposed by historicity, most, if not all, decisions in organizations are made in uncertainty'. Levels of uncertainty, however, depend on the complexity and changeability of the environment (Damanpour 1996).

The distinction between risk and uncertainty is important because, in general, individuals are more averse to uncertainty than risk (Fox and Tversky 1995). It is important to be able to tolerate, and have competence to manage, risks and uncertainties (Kahneman and Tversky 1979). Although the distinction has been applied to tourists' willingness to take risks, it has not been applied to tourism entrepreneurs (Williams and Baláž 2014). 


\section{Categorizing the pervasive risks and uncertainties of the innovation process}

Lane and Maxfield (2005, 3) ask: 'what are innovating agents uncertain about, and how does their uncertainty affect how they act?'. There have been several categorisations of the types of uncertainties encountered, and Jalonen's (2012) generic review identifies eight main types: technological, market, regulatory/institutional, social/political, acceptance/legitimacy, managerial, timing, and consequence. These are broadly similar to the classifications of different types of risk categories (Shook, Priem, and McGee 2003).

However, because our focus is on entrepreneurs' understanding of the often blurred and shifting nature of risk and uncertainty throughout the innovation process, it is also useful to draw on the product development literature. Specifically on Keizer et al. (2005) who provide a simpler but inherently more flexible focus on four broad risks: 1) technical risks are mainly concerned with the complexity of the technological environment and the impossibility of foreseeing obsolescence or changes, lack of technical capabilities or customers' lack of understanding of the technology; 2) market risks involve customer resistance because of perceived risks, lack of understanding of the innovation value, and difficulties in forecasting sales; 3) financial risks concern the financial feasibility of a project (e.g. risks associated with interest rates, budget management, liquidity and investment); and 4) organisational risks involve the internal competences of the firm and its ability to execute strategies and achieve targets with the available resources. Some commentators consider that market risks are least controllable and most difficult to manage (Kim and Vonortas 2014), but all these risks can be encountered in the innovation process.

Engaging with risk and uncertainty 
Risk (known risks) is inherently easier to plan for than unknown risk, or uncertainty. Risk management strategies represent reasoned decision making responses to risks, and typically involve assembling and analyzing information (Bowers and Khorakian 2014), leading to estimates of risks, strategies to mediate these, and consideration of the extent of the remaining (known) uncertainties. Rarely are such strategies applied to the innovation process (Barbosa, Kickul, and Smith 2008), especially in smaller, resource-constrained enterprises. This is surprising as the project management literature indicates that competences to manage risk/uncertainty are essential, although based on patchy and unreliable knowledge (Lee and Jang 2007, 56).

Various strategies can be employed to avoid, transfer, mitigate, or absorb risks, at least partially (Smith and Merritt 2002). However, uncertainties are necessarily resolved only as the project progresses, and as key factors and outcomes become concrete and visible (Thomke and Reinertsen 1998). However, only when a product finally competes in the marketplace (Park 2010) are the realities of the risks and uncertainties fully manifested. Before that, they will have emerged and shifted and changed throughout the innovation process as discussed below.

The effectiveness with which entrepreneurs engage with, and manage, these shifting risks and uncertainties depends on the dynamic capabilities of the enterprise, that is 'how it integrates, builds, and reconfigures internal and external competences to address changing business environments' (Teece et al. 2016). Managerial (entrepreneurial) agility is the key to the management of demand shocks and supply-side uncertainty (Teece et al. 2016, 17). The development of the enterprise's dynamic capabilities are dependent on the bounded learning capacities of individual entrepreneurs (Jovanovic 1982): many only really understand their ability to manage uncertainties after the innovation process is complete, leading to failed or ineffective innovation processes. Additionally, because innovation is a transformational 
process (Jalonen 2012), the lack of precedents means that innovation is as, or even more, likely to require intuitive than reasoning models (Kahneman 2003). The balance between the two models shifts over time (Olson 1985): for example, intuition is more likely to be important at the idea generation and opportunity identification stage, while reasoned approaches are important in the evaluation of marketing opportunities and implementation stages. Overall, innovation is a process of muddling through (Rehn and Lindahl 2011).

Changing interplay of types of risks, uncertainties and strategies across the innovation process

Innovation as a process is the sequence of events that entrepreneurs engage with to transform a new idea into an implemented reality (Van de Ven et al. 1999). While the changing nature of the enterprise to manage uncertainties has been recognized, particularly in the concept of dynamic capabilities, far less is known about the changing nature of risk and uncertainties during the innovation process. Different types of risk and uncertainties pervade the innovation process but are shifting. Since Levitt's (1965) discussion of a 'product life cycle', researchers have attempted to understand the obstacles confronted in each phase of this cycle (Jawahar and McLaughlin 2001; Masurel and Van Montfort 2006). There is broad consensus that entrepreneurs face the most significant challenges in the early stage of business formation and development (Fisher, Kotha, and Lahiri 2016) as they encounter what Stinchcombe's (1965) terms the "liability of newness": 1) lack of role models; 2) lack of standardized communication channels; 3) lack of trust and credibility; and 4) lack of established clientele. However, Bowers and Khorakian (2014) emphasise that unacceptable risks often only become evident in the later stages of the innovation process. 
The innovation process is non-linear, but for the purpose of this analysis can be understood as unfolding through four main, often overlapping and sometimes non-sequential, stages (Kanter 1988): idea generation, coalition building, idea realization and transfer or diffusion. This framework has been used to analyse the tourism innovation journey by Rodriguez et al. (2017). The literature on entrepreneurship and innovation emphasizes the role of coalition building as a strategy of risk identification and management rather than a stage itself (Pittaway et al. 2004), and that approach is adopted by this paper. Inconsistencies between the innovation stages complicate the attribution of risks to specific stages, some of which are prevalent in the entire process while others become manifest at a particular stage but are rooted earlier in the process.

\section{- Idea generation}

Innovation begins when entrepreneurs sense a new opportunity. This discovery task can be a source of uncertainty especially if the gap identified is not closely aligned with the customers' needs (Rodriguez, Williams, and Andreu 2019). After the discovery, the innovative idea is repeatedly evaluated through engaging with informed individuals, undertaking preliminary market testing or financial viability analysis (Rodriguez et al. 2017). This is a critical moment when, depending on the availability of information, the estimated costs and returns can be revised to take into account risks. However, there is also considerable uncertainty rather than risk at the ideation stage since firms have acute difficulties in forecasting both the course of product development, and sales (Kim and Wilemon 2002) because of limited, often informal and approximate, information (Luoma and Paasi 2007). Understanding future markets is critical: innovations largely fail due to poor market analysis (and uncertainties) rather than technical product shortcomings (Ogawa and Piller 2006). 
Securing timely and reliable knowledge about customer requirements is the most obvious strategy (Ogawa and Piller 2006) but entrepreneurs also reach out to their personal contacts for knowledge, and to help recognize the potential for entrepreneurial opportunities (Jack 2005) and validate their idea. This can also help them to develop agility to cope with uncertainty (Zahra and George 2002). However they are especially likely to have to rely on intuition as much as reasoning at this stage (Olson 1985).

\section{- Idea realization}

This involves turning the idea into something tangible (Kanter 1988), and engaging with the associated critical organizational challenges. There may be a growing realisation of limited understanding of customer needs, poor definition of product requirements and insufficient technological knowledge, that is a mixture of risk and uncertainty. A key strategy is to engage in quick, iterative and mostly small experiential actions providing rapid learning (O'Connor, Ravichandran, and Robeson 2008), including prototyping and extended trials for potential customers who can become active co-developers (Cui and $\mathrm{Wu} 2016$ ). The aim is either to convert uncertainties to risks, or to estimate risks with greater precision.

Organisational emergence can also lead to new risks and uncertainties linked to assembling a working team (organisational risks), and raising capital (financial risks). Human resource risks are common, related to recruiting skilled staff (Shepherd, Douglas, and Shanley 2000), as are risks associated with external outsourcing of key tasks. Competency gaps increase awareness of uncertainty.

Typical strategies to deal with such knowledge gaps are the creation of advisory boards, selfeducation (do it yourself strategy) and formal educational or training programmes. There may also be significant changes in networking, as entrepreneurs reach beyond family and friends to former and new business contacts and friends of friends (Jack 2005). Bootstrapping can 
also reduce the risks associated with access to resources, especially reliance on long term external finance (Winborg 2009): these include the owner working below the market salary level, sharing and borrowing resources, operating from home and hiring temporary staff. Such strategies seek to prepare for uncertainties, but despite the continuing dynamic development of capabilities, individuals still have to rely on intuition, chance and guesswork (McKelvie, Haynie, and Gustavsson 2011).

\section{- Transfer or diffusion}

The innovation process culminates with the commercialization or adoption of the innovation, the moment of truth when the assessment of risks and uncertainties is ultimately tested. Most innovations fail because of limited market understanding and failure to overcome customers' resistance (Kleijnen, Lee, and Wetzels 2009; Heidenreich and Kraemer 2015; Rodriguez et al. 2019), probably the most persistent of uncertainties, although the appearance of unanticipated competitors and poorly timed market entry are also important. Technological issues also emerge either because it is inadequate (poorly managed risk), or is undermined by unforeseen competing technologies (uncertainty).

A range of strategies are available to deal with customer resistance. Information and communication strategies can reduce the perceived risk for consumers and engender trust (Oreg and Goldenberg 2015), a 'lubricant' to facilitate cooperative exchanges in the face of uncertainty (Dasgupta 1988). Entrepreneurs may also actively search for business partners and formal business associations to enhance their reputation (Jack 2005), and improve how they scan and interpret knowledge in response to uncertainty (Lang, Calantone, and Gudmunston 1997). Communication strategies can include experimentation through demonstrations (Heiman, McWilliams, and Zilberman 2001) which allow customers to experience/learn from the product before purchasing. By this stage the entrepreneur may have 
significantly enhanced his/her, or the enterprise's dynamic capabilities, but there are limitations to learning (Jovanovic 1982) so this is also the moment when earlier reasonings or intuitions are cruelly exposed.

\section{Research focus}

Based on this literature review, the paper addresses two research questions. First, how do tourism entrepreneurs understand risks and uncertainties across the different stages of the innovation process? And, secondly, how do tourism entrepreneurs manage these risks and deal with uncertainties across the innovation process?

\section{Methods}

In response to the relatively weakly-theorised nature of this topic, and the complex interactions in the entrepreneurial innovation process, a qualitative methodology with indepth interviews was adopted (Miles and Huberman 1994). This provided a thick description of the understanding of risks and uncertainties, and entrepreneurial strategies to mitigate or reduce these.

The first challenging step was the identification of innovative tourism entrepreneurs when there are no systematic databases. Therefore, participants were selected using snowball sampling, as is usual when investigating hard-to-reach populations (Goodman 1961). Respondents were initially approached via contacts with known innovative entrepreneurs and key informants, such as professional bodies and industry organisations, universities, government agencies, acceleration programmes and entrepreneurial communities. Then two main criteria were used to identify innovative entrepreneurs and reduce some sources of variation in the sample: 1 ) degree of novelty (from incremental to radical according to Schumpeter 1934) in order to select innovative as opposed to replicative entrepreneurs 
(Baumol 2010); 2) start-ups purposely created to develop the innovation but at different stages of their business lifecycle (excluding corporate innovation in incumbents). This means their focus is driven by product innovations which is considered especially prone to risk and uncertainty (Stevens and Burley 1997). We do not differentiate between radical versus incremental innovations, it takes time for this to become evident. In practice, most innovations were likely to be of different shades of incrementalism. Also the focus was only on live companies since studying failed entrepreneurs poses significant and different methodological challenges/limitations: it is usually more difficult to identify individuals who have closed their firms (e.g. they tend to disappear quickly from most databases) and to interview them (e.g. recent failures can be painful to discuss). It is however acknowledged that they would have different stories to tell about the understanding of risk and uncertainty, and of their unsuccessful attempts to manage these.

All suggested entrepreneurs were discussed and validated within the research team before being approached. Detailed desk research provided information about each founder entrepreneur and the business prior to the interview, which significantly enhanced the trust between interviewer and entrepreneurs (Marshall and Rossman 2006), while also providing context. The firms were all SMEs, the predominant organizational form in tourism, and they are also considered to have intrinsically higher levels of uncertainty (Storey and Sykes 1996). Virtually all entrepreneurs focused on product innovations rather than process, marketing or organizational innovations.

The final sample was constituted of 28 entrepreneurs in the UK and 29 in Spain. The choice of these two countries was informed by an initial expectation that different entrepreneurial and innovation contexts (e.g. Spain has developed strong governmental programs of support to innovative entrepreneurs, while the UK presents a more neoliberal context based on attractive tax incentives) could have potential to shape innovation and risk management. The 
choice was also informed by the composition of the team and their possession of appropriate networks to initiate the snowball sampling. As the findings did not identify any major cleavage between UK and Spanish entrepreneurs in terms of the importance of contextual or macro-scale environmental factors, they are not differentiated in the findings section; this is further commented on in the discussion.

The interview questions were organised around 4 key themes: overall innovation process, risks and uncertainties understood and experienced, specific risks and uncertainties related to the stages of the innovation process, and management strategies. The difference between risk (known risks they were aware of and had some notion of their likelihood) and uncertainties (unknown, or known to exist but impossible to estimate their importance) were explained during the interviews. This design responds to Leisch et al's (2011) comment that researchers have rarely asked entrepreneurs to differentiate between risk and uncertainty. While acknowledging potential post-hoc rationalization of past events, retrospective interviewbased research is common in management studies (Cox and Hassard 2007).

Most interviews were conducted between November 2016 and February 2017 in English and Spanish in person, but Skype was used when this was impractical. Each interview lasted an hour on average and all were audio recorded, fully transcribed and analysed using Nvivo software.

The interview process continued until theoretical saturation was reached (Eisenhardt 1989; Bowen 2008): when the team agreed that no new categories or themes were emerging and/or altering the previous codified data. The main themes had already emerged after some 30 cases while additional interviews were undertaken to consolidate these and draw out different nuances in the narrated experiences of a purposely heterogeneous sample within our broad selection criteria. 
The method chosen to analyse the understanding and management of both risks and uncertainties was thematic analysis. This is an accessible and flexible analytic method, considered a methodological approach in its own right (Braun \& Clarke, 2006). The process of analysis comprises six key stages which favours a systematic treatment of data and the identification of themes through an inductive approach after the authors' initial familiarisation with the data while transcribing, iteratively reading and data coding. Coding aims to identify concepts, in our case, mainly types of risks and uncertainties. Those codes which seemed interconnected were grouped together under a theme. Themes need to be defined, named, reviewed and refined ensuring they formed a coherent pattern. Extracts from the transcriptions are selected to support the validated theme (see example of coding at Table $1)$.

Table 1 here

During the research process rigor and trustworthiness were attained through substantial application of evaluation criteria relevant for qualitative studies, that of dependability, credibility, confirmability and transferability (Lincoln \& Guba, 1985). Detail description of the process and inclusion of the entrepreneurs' life situations meets the dependability criterion. Credibility implies that understanding of the researched phenomenon will arise if the study participants are part of the investigated issue (entrepreneurs in the tourism and hospitality sector who innovate). Attention was given to sampling adequacy: the individuals selected were those who had the best knowledge of risk and uncertainty being founders of the companies and living first-hand the innovation process. In addition, during the interview process we were constantly summarizing to the participants the risks mentioned in the previous stage in order to confirm these with them. For example, we introduced questions which involved checking and confirming such as "in relation to the previous risks you mentioned- and these where repeated again to the participant- where there any changes in 
risks, which new ones emerged? Audit trails to document the course of analysis development, and member checks when coding or categorizing (Lincoln and Guba 1985), were applied to meet the confirmability criterion. During the data analysis process, all researchers dealt separately with a selected number of interviews. During the process the developed and assigned codes and overall understanding of identified codes were constantly compared. We also ensured informational adequacy assessing the relevance, completeness and amount of information obtained (data saturation) and provided sufficient detail of the investigated context and the actual fieldwork. This enables researchers to determine their confidence in transferring results and conclusions to other contexts and situations, thus meeting the criterion of transferability (Lincoln \& Guba 1985).

\section{Profile of entrepreneurs and innovations}

All interviewed entrepreneurs are active co-founders of innovative tourism firms. $81 \%$ are men aged 25-45, possessing a university degree, with diverse academic backgrounds. Only $12 \%$ have tourism or hospitality related degrees and 30\% hold Masters level qualifications in business studies. While $48 \%$ of the entrepreneurs have previous experience of owning and managing small businesses, only $15 \%$ were tourism related. However, $41 \%$ have professional backgrounds in the tourism sector. The most important motivating factor to start a venture was to spot a market opportunity, with the majority of entrepreneurs reporting that acceptance of risk and a vision were a crucial element of the entrepreneurial journey. A small but important minority, $15 \%$, have failed in previous attempts to innovate. The vast majority of entrepreneurs either already had grown their businesses or are in the process of business growth. Also, the majority aim for international expansion. The businesses incorporate a variety of innovative practices in both more traditional hospitality (hotels and restaurants) and travel businesses (e-business niche travel agencies), but there is a dominance of technology related innovations with a business-to-business (B2B) orientation. These 
technologies focus on increasing tourism firms' efficiency in different aspects such as food waste, human resources management, service quality, and relations with suppliers. They also aim to add value to the customer experience: e.g. more visual and interactive forms of communication and promotion, and increased accessibility to resources and services. See Table 2 for a more detailed description of the innovations.

Insert Table 2

\section{Findings}

\section{Level of risk and uncertainty attached to the new venture}

Entrepreneurs views about the initial level of risk and uncertainty attached to the innovation were polarized between those who considered it low risk versus high risk with considerable uncertainty. Those who considered it low risk explained that this reflected their confidence in their experience as entrepreneurs or in the sector. Unsurprisingly, they considered themselves risk tolerant and were not put off by the uncertainty of the project. Only two entrepreneurs in this group openly recognized they had been over-optimistic about the risks and uncertainties as this entrepreneur, offering an AR guided system to museums, comments:

$$
\begin{aligned}
& \text { It is my first time as entrepreneur and I realized later that I had focused on my } \\
& \text { technical capacity to develop augmented reality software while neglecting the } \\
& \text { market's willingness to acquire my product [I6]. }
\end{aligned}
$$

Their evaluation of the risks was also associated with the personal/financial investment involved. Those who were relatively young, without family responsibilities, or had 'nothing to lose' in terms of career opportunities being dissatisfied with their previous jobs, had relatively low switching costs. Where entrepreneurs had low asset or fixed costs, and the launch was relatively small scale, they mostly considered the financial risk as low, representing an affordable loss. 
In contrast, the majority who considered the project was 'high risk' were influenced by four main considerations: 1) the high level of uncertainty attached to innovation in general or to their specific projects (e.g. disruptive food concepts). As this entrepreneur explains:

When you do something innovative and disruptive the probability of error is higher since there are no references in the market to know if it is going to work or not [I15]

2) financial risks because of the scale of the innovation and associated investment (e.g. high technology costs, investment in a hotel asset, etc.); 3) personal risk in the context of family commitments, and reputational loss; and 4) individual attributes such as lack of initial knowledge or industry experience, contributing to uncertainty. For example, a tech engineer states: We did not have any knowledge of the tourism market and this is an important risk [I5] and the owner of a travel agency reports: we both had experience in travelling but not in selling travel or any experience in the travel industry. We went in blind [I39].

Despite the high levels of uncertainty and risk, they had still decided to act on the innovation, driven by their vision, and a mixture of analysis, and intuition, of the balance between rewards and costs. A small minority recognised they had only realised the magnitude of the risks and uncertainties after they had started. In general, the evaluation of there being high levels of risk and uncertainties decreased as the project progressed and goals started to be achieved.

\section{Risks, uncertainty and strategies at the idea generation stage}

Understanding of risk. The most important risks identified at this stage were financial: the start-up costs and the risk of failure (see Table 1 for detailed examples in quotes). Most entrepreneurs had concerns about the consequences of failure, whether in terms of funding or opportunity costs. Some entrepreneurs also mentioned how the loss of personal reputation 
could impact on future professional relationships. In relation to financial risks, unsurprisingly the level of investment (e.g. costs associated with a hotel asset) and their source (e.g. external credits versus personal savings) influenced the understanding of risks. There had also been concerns about the risk of being unable to secure sufficient funding to complete the innovation process, or of having underestimated the costs. Many of the more forward-looking entrepreneurs had foreseen market risks associated with the willingness of some tourism subsectors (hotels, travel) to engage with innovations; For instance, this entrepreneur describes the travel sector as:

Easy to enter but difficult to reach volume to make money because it is very competitive, global and fragmented, customers' decision making processes are long and making a big scale business implies high levels of automation [I27].

Understanding of uncertainty. This was a recurrent and important theme among all interviewed entrepreneurs at this stage. Many different factors generated uncertainties. Considerable uncertainty existed concerning future demand for the product. As one entrepreneur explained:

The only thing that was keeping me awake at night was that we were about to build a tech solution that I was not sure was going to be acquired. I was not going to know this until I had the innovation built and priced [I21].

Another source of uncertainty was linked to the challenge of executing the idea into something tangible and aligned to the original conception. This spilled over into forecasting and planning since for novel innovations there are no referents in the market to forecast or estimate the probability of outcomes. Market uncertainty was especially pronounced amongst those who had no prior knowledge or experience of the tourism sector as this comment from a hotel entrepreneur illustrates: 
Imagine the uncertainty of a person who does not know the sector in which he/she wants to enter... what I did it was suicide and I totally advise against it [I1].

Another market related uncertainty was the lack of knowledge of competitors' behaviour and especially the fear of being imitated or, even worse, that more agile firms would arrive at the market before them. For those developing technological innovations, uncertainty emanated from the dynamism and rapid obsolesce of technologies. Additionally, some breakthrough technologies were still at an incipient stage of development (e.g. 4D augmented reality teleportation cabins allowing customers to experience holiday destinations) with uncertainty as to whether they could be realised.

Strategies to address risk and uncertainty. Many entrepreneurs used bootstrapping strategies to address financial risks: these were mostly, founder-related such as working on the project without salary or holding parallel jobs. However, strategies can generate new risks, especially in the early stages of learning about these: for example, working in other jobs may distract them from the project. Other bootstrapping strategies include saving on space costs by working from home, university or co-working spaces. A few entrepreneurs also emphasised the importance of winning tourism innovation awards which provided small scale funding and enhanced their project's profile, and individual self-confidence.

Uncertainty, is inherently difficult to address, and small scale market research studies, lacking in rigour, my lead to overconfidence. Typical strategies were the development of pilot versions of the final innovations for market testing or the celebration of proof of concept events (e.g. a restaurant organizing thematic events). Some worked cooperatively with the target market, asking for feedback and information about their needs, in at least a semblance of co-production as illustrated by this entrepreneur working on food waste technology for hospitality businesses: 
We minimized this by spending a lot of time on due diligence, talking and making checks with customers, "this is what we're going to do", "shall we do this", "how would you want it to look on your phone" but because the technology wasn't live we still didn't know whether it would work or not. [I19]

To some extent, these measures did convert some uncertainties to risk. However, only one entrepreneur undertook a formal risk assessment before moving to the idea development stage despite the potentially high risks. Bootstrapping, as commented above, was the most common means of managing these risks or minimizing vulnerability to uncertainties while others decided to plough on, driven by a sense of (over) confidence and relying on intuition as the following example of an online booking platform illustrates:

I rely on my intuition but I did not have much choice. With scarce resources you have to make a quick analysis of the situation and act based on the evidence. I managed to make my way with a mixture of risk, intuition and speed [I33].

\section{Risks and strategies at the stage of idea development}

Understanding of risk. Financial risk is again most prominent but there have been changes in how this is understood, reflecting their learning about the widening gap between expenditure and revenue. 11 entrepreneurs reported that cash flows were one of the biggest risks due not only to weak or absent revenue stream but also to delays in securing funding from private investors. The interviewees considered there were risks associated with seeking private capital investment: 1) loss of control; 2) the unpredictable, short termism and metric-driven nature of risk-averse investors; 3 ) the time-intensive and complex nature of engaging with investors (described as "a massive distraction and a full time job" by the majority of the 
entrepreneurs); and 4) lack of knowledge about how this environment works - that is a degree of uncertainty as well as risk.

Organizational/operational issues are the second type of risk commented on. The main operational risks are associated with the time-to-market and the need to shorten the development cycle. One common response is to approach potential customers with a Minimum Viable Product (MVP), an interim version of the innovation. However, entering the market with an imperfect product is itself understood to constitute a risk. Another source of risk is unanticipated operational costs (uncertainty being transformed into known and substantial risks) and deviation from the initial business plan. Entrepreneurs also report that the management of organizational resources is another source of risks, especially: the time required to deal with diverse tasks, losing focus and being unable to maintain a clear strategy, poor recruitment as they seek to expand the team, and over-reliance on a single founder.

Understanding of uncertainty. Uncertainty is a recurring concern for many entrepreneurs because of the range of events that is beyond their control from execution to market. In terms of execution, one entrepreneur building an innovative hotel concept had concerns that the lack of a specific regulatory framework could affect the innovation process:

We were building a totally different hotel concept in nature and we did not have a legal framework to adhere to. The tourism administration did not know how to categorise us so I was working with the fear that tomorrow I was going to wake up with an email-bomb of who knows what ...: the engineer cannot solve a technical problem or suddenly a building license gets stuck ... There is a high probability that something will occur that will stop everything but right now you are incapable of knowing that it even exists. [II] 
Entrepreneurs further explain that regulations and institutional frameworks are acting simultaneously as a source of both certainty and uncertainty, illustrated by the following example of a platform (similar to Airbnb) offering local homes to the tourism market:

Legislation is a massive risk to us as a business and our ability to grow longer term in our industry because if a city decides that you're not allowed to rent your home shortterm then we don't have a business in that city any more. [I34]

The lack of skills and knowledge were also causes of uncertainty. These include industry knowledge gaps (e.g. travel legislation) and technical knowledge deficits (e.g. sufficient knowledge of artificial intelligence to develop virtual tourism).

Similar uncertainties to the previous stage existed, although these were usually made more acute by the approaching market entry, including the fit between product and market needs, and the uncertainties of introducing radical new products with no precedents. Agile competitors and the possibility of being imitated by other companies were also persistent market uncertainties.

Strategies to address risk and uncertainty. In order to minimize financial risk at this stage, a range of new bootstrapping HR-strategies are added to the founder-related and working-space strategies of the previous stage. This is given urgency by the challenges that small startups, with limited resources, experience in matching the competitive salaries required to recruit or retain knowledgeable staff.

More than half of all entrepreneurs reported using different bootstrapping techniques in this respect: hiring on a temporal basis or for specific tasks, sharing employees with other firms/active projects (especially in co-working spaces), internships, employing newly qualified engineers, voluntary wage reductions or employing friends and family. However, 
on reflection, some entrepreneurs regretted these strategies as generating alternative risks such as reduced commitment and professionalism.

Risk transference via outsourcing or hiring outside experts for specific tasks (e.g. digital marketing, accountancy) are also important as this entrepreneur explains:

Nowadays it is relatively easy to reach specialized knowledge on specific platforms at very reasonable prices. [I14]

However, most entrepreneurs recognized the risk associated with leaving technology developments in the hands of external companies, which could be unreliable in terms of costs, timing, and commitment to the project as illustrated by the following comment:

If you are not an engineer and your product is a tech platform, it is reasonable to think short-term on outsourcing but this is a mistake. As the product evolves you need to change many things and this increases the costs and you can't count on a person who is fully dedicated to the project. It is preferable to do this internally through hiring or having a tech partner [I31].

A vast majority of the entrepreneurs mention bootstrapping measures to control costs and minimize expenditure on staff (e.g. numbers on shift), leasing equipment, transportation costs (avoiding unnecessary trips), marketing (asking customers to be content advisors, or using free online tools) or office space (e.g. meetings in hotel lobbies). Organisational effectiveness helps entrepreneurs to minimize organizational/operational risks and implies flexibility, internal specialization of tasks or division of labor, automation, and effective HR policies and communication. Another approach entrepreneurs reported is the "do it yourself" in house strategy, but this required intensive learning about how to perform many different tasks (especially marketing) as part of the expanding dynamic capabilities of the enterprise. The 
outcomes sometimes are basic and non-professional, which poses different risks. This is well exemplified by this entrepreneur commercialising multisensory dining experiences:

I said okay, let's be creative ... and we decided that everything was going to be served on a rectangle. I looked online, the rectangle plates were about 18-19 pounds each. I didn't have 2000 pounds to spend, so we looked around ... and we finally took kitchen tiles!! [152]

Dynamic capabilities are also expanded in other ways. In order to minimize organizational/operational risks and uncertainties related to knowledge gaps, which are especially acute in tourism, the entrepreneurs work on incorporating key missing knowledge through creating advisory boards (private investors, lawyers, technology experts, etc.). A minority also report engaging in extensive networking with tourism industry experts, investors and other entrepreneurs to learn from them, engaging in formal learning as this architect entrepreneur who comments:

Before starting to build the hotel, I enrolled on a course of hotel sales management at university not only to get basic knowledge but also get to know people from the sector and build contacts [I1]

They also initiated a process of autodidactic learning and learning by doing as exemplified by this entrepreneur who developed an app for hotel laundry services:

Taught myself how to programme, all the accounts, selling, everything and then we've employed people to take over those roles, who are far better than we ever could be [I13].

This strategy of do-it-yourself and deferring the process of hiring specific skills until the business can sustain their costs is, however, itself a source of risk for entrepreneurs (e.g. intuitive procedures, delays, poor quality). 
Risks and strategies at the stage of innovation diffusion

Understanding of risk. As companies grow, entrepreneurs report an exponential increase in risks in terms of financial resources, fund raising, asset investment and accumulated debt, whether their loans were from the private or public sector.

The most important type of risk at this stage, however, is market related with customer resistance to innovations being highlighted by the vast majority. Lack of reputation or market credibility, in the case of start-ups, or newcomers to tourism, also added to the risks. Paradoxically, entrepreneurs report that these sources of market risk are generated by the customers' own uncertainty. Some risks reflect fears (e.g. loss of autonomy), while others are psychological (e.g. the innovation did not cohere with customer self-image), privacy (requires collection of personal/confidential information), safety concerns and investment of effort and time. Entrepreneurs partly attribute the resistance to the characteristics of the hospitality market: being satisfied with the status quo and low appetite for their technological innovations or interest on the aspects these aimed to solve as illustrated by the following example:

Our platform targets hotel companies with corporate values such as transparency, communication and collaboration. There are still many companies which fear transparency and don't have any interest in developing HR and motivating people. [I11]

Entrepreneurs were also now more aware of the intensity of competition as they entered the market:

If you have a good product that fits well in the market, it is common that new alternatives and ideas will come up and we are seeing an increase in competitors in the taxi sector [142] 
They were also consious of how greater visibility exposed them to imitation by larger, betterresourced firms: Google's is competing with everyone, with everything [I12].

There are also organizational /operational risks familiar from the previous stage, but now intensified by the expansion of sales: such as maintaining the initial quality levels, and incorporating new HR practices and skills to attract or retain skilled workers. The technological uncertainty of previous stages is replaced by technological risks at this stage, mainly associated with safety and data protection.

Understanding of uncertainty. Uncertainty at this stage is mostly market-related, derived not only from market risks but also associated with the unknown and difficult-to-predict behaviour of customers. The owner of an online travel agency specialising in glamping accommodation illustrates this:

The sensation of risk and uncertainty never ceases really. The only thing that changes is your ability to manage them: either you suffer a heart attack or not. There is an everlasting risk of yesterday we had customers and today I don't know what happens... Recently, during the same week we had the best turnover day and the worst of our history... [I33]

Uncertainties are also exacerbated because those seeking first mover advantage were more likely to encounter an unreceptive or unready market; disruptive concepts especially faced uncertainty as this entrepreneur illustrates:

At the beginning my food proposal was so radical that people seeing the menu were soon leaving and I seriously considered closing [I46].

Entrepreneurs also report on organizational/operational uncertainties associated with new growth challenges, mainly how to increase revenue and expand the customer base as they move beyond the most obvious targets. The uncertainty increases if the firm is 
internationalizing, because of gaps in their knowledge of legislation, consumer cultures or business norms.

Strategies to address risk and uncertainty. Strategies to minimize financial risk include a range of bootstrapping techniques already mentioned, with the addition of techniques typical of the market stage such as growth hacking (low cost alternative to traditional marketing). Some tech entrepreneurs also diversify to other sectors and other demand segments, either offering adaptions of their innovations or totally new products as exemplified by the following example:

In parallel to the tourism sector we have been working in the development of a virtual assistant for the 4.0 industry" [I5] or by this: "I have used the same technology I used in guided systems for museums to offer solutions to industry or medicine [I6].

Safety concerns about technological risks tend to be transferred to external companies:

All our hotel clients' data is held by a specialist company, which is expensive but we said we rather take all that out. It's done in that sort of secure sense. We had to derisk, as much as we could afford to, the risks around hacking, corruption and data access. [I16]

A wide range of strategies have been implemented to minimize innovation resistance mostly related to providing customers with information (face-to-face or videos) about the benefits of the innovations. Strategies implemented at an earlier stage, such as offering demonstrations or free trials, are again emphasized. Building trust and generating credibility are also seen as important, especially networking (e.g. with trade associations, or through training). A final important strategy is targeting innovators and early adopters who are more likely to be receptive and are key to escalating innovation within organizations. 


\section{Discussion}

As risks and uncertainties, especially market uncertainties, are recognised from the initial stage, they are integral to the entire innovation process. Questions related to the commercialisation of the innovation must be taken into account from the concept design to idea development and launch (Luoma and Paasi 2007). This applies to both those who had initially considered the venture to be high risk, but proceeded, and low risk, a difference that reflects not only personalities and individual circumstances, but also the degree of novelty of the innovations. Individuals are generally overconfident about their competence to manage risks (Camerer and Lovallo 1999) but in this study only two entrepreneurs openly recognized, retrospectively, they had underestimated the innovation risks.

Disaggregating the risks and uncertainties, shifts can be seen over time in the relative importance of the four generic types (Keizer et al. 2005) as well as in how they are articulated. Financial risks were most prominent in both the idea generation and the idea development stage, but whereas the focus initially was on the costs and risks of failure, by the second stage it had shifted to liquidity risks. There were also changes between the two stages in the relative weight attached to the other generic risks. Whereas technological and market risks and uncertainties had been important in the idea generation stage, they were subsequently partly supplanted by organizational/operational risks. In the diffusion stage, market uncertainties were most important, as the entrepreneurs came face to face with customer resistance, or sector conservatism. Regarding uncertainties, the most important decisions with the greatest implications are made in the early stages of the innovation process when the entrepreneurs' knowledge (including tourism knowledge) is relatively limited, as are their other resources including time. As Souder and Moenaert (1992) state, the early stages of the process are uncertain due to the 'high perceived variability and low perceived 
analyzability of the tasks in question. As the innovation process progresses and more information becomes available, variability will decrease and analyzability will increase'.

Entrepreneurs are not passive recipients of risks and uncertainties; instead, tolerance of, understanding of, and strategies to engage with these are essential to entrepreneurship (Schumpeter 1934). But proactivity is not risk free, as interventions are made in context of pervasive uncertainties: in effect, the entrepreneurs are aiming at moving targets.

Consequently, their strategies generate new risks. For example, outsourcing knowledge and skills, or 'do it yourself' approaches, can be optimal short term strategies when resources are tight, but bootstrapping can be detrimental to longer term firm performance (Ebben 2009). This highlights how lack of knowledge is at the heart of the risks and uncertainties faced by entrepreneurs (Williams and Baláž 2014). Two types of lack of knowledge were especially evident in our sample: those who developed products with high tech reliance, but lacked technological expertise, and those who had entered tourism with little sector knowledge because of low entry barriers. In response to these challenges, networks are a key source of resources and knowledge, especially for small firms (Pittaway et al. 2004), and critical to improving innovation outcomes (Gronum, Verreynne, and Kastelle 2012). For instance, during idea generation and development, when entrepreneurs face high uncertainty, they reach for their personal ties, such as families, friends or industry colleagues, to validate their idea and for funding. At this stage entrepreneurs are also coping with the 'liability of newness' (Stinchcombe 1965) and may have limited contacts. When assessing the potential market for their idea, they expand their initial network, activating tourism industry representatives and key experts. During the innovation lifecycle, entrepreneurial networks grow in size, but also are constantly reconfigured according to the changing needs of the process, incorporating more specialised industry-specific actors, to open up opportunities, diminish uncertainties and manage risks. 
Risks and uncertainty are not exceptional but are pervasive to the entire innovation process. The dynamism of both the innovation process and of risks and uncertainties, as well as scarce resources, force entrepreneurs to accept and absorb risks and uncertainties that they can, at best, only see vague outlines of. Perhaps overconfidence and over optimism are necessarily parts of the 'job description' of being an entrepreneur, linked to a willingness to trust intuition when faced with uncertainties. Of course, the entrepreneurs' competences are also not fixed because the innovation journey provides a learning opportunity (Bowers and Khorakian 2014). Given the life versus death nature of the risks and uncertainties, it is a very steep learning curve. Some entrepreneurs do become more analytical but the number who reported they had used formal risk assessment increased from only one to six over time, a small minority. Instead, they become more knowledgeable, and develop a better understanding of the nature of risk. But there are limits to the acquisition of knowledge, and about a fifth of the sample openly recognized they were ultimately reliant on intuition: as Styhre (2004) emphasises, intuition takes over where knowledge ends. In part this explains the paucity of formal innovation risk management strategies in SMEs (Barbosa et al. 2008). Many of the risks and uncertainties, and the strategies to engage with these, appear generic, rather than tourism specific, that is challenges that apply to tourism as to any or most other businesses - although that cannot be confirmed until the production of similar research in other sectors. In some ways, this reflects the fact that most respondents focused on internalto-the-firm rather than external or contextual risks and uncertainties, some of which such as seasonality are highly tourism specific. Nevertheless, a number of tourism specific features do seem to be important in shaping the findings of this research.

First, as noted in other research, the tourism industry has been attractive to entrepreneurs with little previous knowledge of the sector (Rodriguez et al. 2017), due perhaps to both the ubiquity of tourism experiences as consumers, and low entry barriers. This may promote 
excessive levels of overoptimism and overconfidence (Simon, Houghton, and Aquino 2005; Camerer and Lovallo 1990). This spills over into a tendency to view tourism as a fertile ground for experimentation, especially technological experimentation, on the grounds of the apparent dynamism of the system, while being unaware of high turnover rates in the sector. However, this is an issue that requires further investigation involving failed innovations, and entrepreneurs. Second, many of these tourism entrepreneurs focus on niche products, and their innovations are relatively easily imitated (Hall and Williams 2008) or constitute micro markets (such as that for glamping) which are difficult to break out from. Moreover, small, poorly resourced, companies can quickly become vulnerable to imitative innovations by large companies. This connects with the challenge of scalability, as these small firms seek to expand and need to engage with what to them, compared to larger existing companies, are the risks associated with standardisation to reach a larger market share.

Third, the well-known weak propensity of tourism firms to collaborate, or enter partnerships, when innovating (Hall and Williams 2008) also shapes their engagement with risks and uncertainties. Fourth, observed entrepreneurial behavior also challenges the prevalent view of tourism entrepreneurs as lifestyle entrepreneurs who avoid business growth and associated risks (Thomas et al. 2011). Our findings show that entrepreneurs enter the tourism sector because of the market opportunities but also perceiving tourism to be an attractive sector as it enables entrepreneurs to engage with their passions or important parts of their lives (e.g. preservation of the environment through establishment of specialized travel agency or a chef who collaborates with scientists to research multisensory flavour perception). There is no evidence that the combination of 'traditional' and lifestyle orientation prevented entrepreneurs from innovating, to grow their businesses and to understand and accept risk as a necessary element of their journey. But it does reinforce the earlier argument about the diversity of the backgrounds of the tourism entrepreneurs, and lack of tourism knowledge, 
and therefore of the associated risks and uncertainties in the case of tourism lifestyle entrepreneurs.

Finally, the study did not reveal major differences among the interviewed entrepreneurs in the two countries in terms of understanding or managing risks and uncertainties. This reflects the fact they focused mostly on more generic internal-to-the-firm risks, rather than on contextual risks such as the regulatory environment, of the extent of seasonality of demand. There were some national differences, with the two most notable being comments on financial uncertainties related to exchange rates as a result of Brexit, and the availability of public loans for tourism innovation being seen initially as helpful in Spain, but ultimately only delaying the risks associated with repayments. However, these were seen as relatively unimportant compared to the main risks reported in the findings section. A word of caution is necessary however about national differences, as qualitative research is concerned with analytical generalisation and transferability, rather than statistical generalization (Stenbacka 2001), signaling the need for research to test identified risk categories through surveys (Miles and Huberman 1994), to exclude sources of bias (such as confirmation bias) and lack of trustworthiness in general.

\section{Conclusions}

Risks and uncertainty are central to the innovation process (knowledge is imperfect and the future cannot be predicted) and to entrepreneurship (being able to accept and manage these). This study contributes the first detailed analysis - generically, and not only in tourism - of the different types of risks and uncertainties encountered along the innovation process, as understood by the entrepreneurs. These require shifting and responsive management strategies, which are informed by their learning. Conceptually, risk can be disaggregated into 
different categories, and the product development literature suggests a fourfold classification: technological, market, commercial, financial and organizational risks (Keizer et al. 2005). Although interlinked and sometimes blurred, this paper has demonstrated that these provide a means of identifying shifts in the types of risk over the innovation process.

A particular contribution of this paper is that it differentiates between risk and uncertainty (Knight 1921). Individuals are more averse to uncertainty than risk (Fox and Tversky 1995) and different competences are required to manage/engage with these (Williams and Baláž 2014). Risks can at least be incorporated into the business plan, and operations: they are in effect 'insurable' (Brouwer 2000). But uncertainty when manifested necessarily requires an agile response by the entrepreneur. Uncertainty was especially important at the idea generation stage, and for those with little prior business knowledge of the tourism sector, with entrepreneurs being aware of the challenges of assessing markets for novel products without obvious existing reference points. Over time, increased experience and knowledge, including tourism knowledge, allows entrepreneurs to convert some uncertainties into risks, in context of the enterprise's dynamic capabilities (Teece et al. 2016), but these persist, and although pervasive to the entire innovation process - become even more focused in the diffusion stage due to difficulties in predicting customer resistance (Kim and Wilemon 2005). This research has limitations, of course, and the first of these is that the sample design means the interviews were with surviving innovators. Those who failed probably have different stories to tell about the understanding of risk and uncertainties, and (failed) strategies to manage or respond to these. Secondly, the study focusses on SMEs which tend to have less resources, and a smaller leadership cohort than larger firms. Thirdly, although - compared to most research in this field - we have disaggregated risk and uncertainty into major categories, there is scope for a more detailed, perhaps case-study based, approach to studying these risks, uncertainties and associated management strategies. There is also a need to disentangle the 
amalgam of risk and uncertainty, as previously noted (Alvarez and Barney 2005): even after the differences between them had been explained, it is clear that respondents often found these were blurred, although there was a coalescence around the importance of what can, and cannot, be planned for or built into business models. Leisch et al. (2011) usefully refer to 'uncertainty acclimatization' versus 'risk accommodation'. This may require adopting the laboratory experimental approach which characterises much of the behavioural economics research in this field. Fourthly, overconfidence and over optimism inevitably colour the entrepreneurs accounts but that is counterbalanced by the fact that how risks are understood is as important as their 'reality'. Fifthly, in common with most qualitative research on the innovation process, the interviews are retrospective and subject to the issues of imperfect memory and post rationalization, which signals the need for 'real-time ethnographic' research on innovation (Hoholm and Araujo 2011).

We conclude by considering some policy and practice implications. First, it is clear that business support services must be provided not only before but after the initial start-up because many key risks and uncertainties only become apparent during the innovation process. In fact, business support services need to target the predominant risks and uncertainties that emerge across the different stages of the innovation process. Particularly important in this respect is the provision of support in accessing tourism knowledge, given the prevalence of entrepreneurs with little or no prior experience of tourism businesses. This is exacerbated by the relatively large number of enthusiasts, and life style entrepreneurs, in the sector. Secondly, the distinction between risks and uncertainties is more than an academic one: different capabilities and strategies are required to address these, and this needs to be articulated in training and business support programmes. A more rigorous approach to riskaware mapping can help with the former, but 'uncertainty acclimatization' (Leisch et al 2012) is far less amenable to this approach. While it was anticipated that tourism innovation would 
be especially vulnerable to uncertainties due to external shocks, most of the findings relate to internal-to-the-firm risks, which emphasizes there is a need for a strong generic component to many innovation support services. Thirdly, self-centred individual learning is central to expanding the dynamic capabilities of the enterprise, and the most effective policy intervention may be to support the development of these competences, rather than formal training programmes which focus on knowledge transfer.

Fourthly, market uncertainties seem to be the greatest challenge faced by innovators rather than technological or financial risks, and these are prevalent at the ideation and the diffusion or commercialization stages (Ogawa and Piller 2006). Various strategies can be adopted to engage with these, including information gathering, demonstration projects, and coproduction. Fifthly, as the findings indicate, resource-poor SMEs require strategic management models that are adapted to their size, but also to their potentially greater agility than larger companies, including relying on bootstrapping, when dealing with risks and uncertainty. Finally, it is important to acknowledge the limitation to interventions: abilities to deal with uncertainty, and to rely on, and value, intuition alongside reasoning are not easily taught, or even learnt. It is essentially a process of muddling through (Rehn and Lindahl 2011), but there are of course shades of muddling, some of which can be addressed. 


\section{References}

Aarstad, J., H. Ness, and S.A. Haugland. 2015. "Innovation, Uncertainty, and Inter-Firm Shortcut Ties in a Tourism Destination Context.” Tourism Management 48:354-61.

Alvarez, S. A., and J.B. Barney. 2005. "How do Entrepreneurs Organize Firms Under Conditions of Uncertainty.” Journal of Management, 31(5):776-93.

Ateljevic, I., and S. Doorne. 2000. 'Staying within the fence': Lifestyle entrepreneurship in tourism. Journal of Sustainable Tourism 8(5):378-392.

Barbosa, S., J. Kickul, and B. Smith. 2008. "The Road Less Intended: Integrating Entrepreneurial Cognition and Risk in Entrepreneurship Education.” Journal of Enterprise Culture 16(4): 411-39.

Baumol, W. 1968. "Entrepreneurship in Economic Theory." The American Economic Review 58(2): 64-71.

Baumol, W. 2010. The Micro Theory of Innovative Entrepreneurship. Princeton, NJ: Princeton University Press.

Beckman, C. M., P.R. Haunschild, and D.J. Phillips. 2004. "Friends or Strangers? Firm specific Uncertainty, Market Uncertainty, and Network Partner Selection.” Organization Science 15(3): 259-75.

Berglund, H. 2007. "Risk conception and Risk Management in Corporate Innovation: Lessons From Two Swedish Cases.” International Journal of Innovation Management 11(4): 497-513.

Bosworth, G., and H. Farrell. 2011. "Tourism entrepreneurs in Northumberland.” Annals of Tourism Research 38(4):1474-1494. 
Bowen, G. 2008. "Naturalistic Inquiry and the Saturation Concept: A Research Note." Qualitative Research 8(1): 137-52.

Bowers, J., and A. Khorakian. 2014. "Integrating Risk Management in The Innovation Project.” European Journal of Innovation Management 17(1): 25-40.

Braun, V., and V. Clarke. 2006. "Using Thematic Analysis in Psychology.” Qualitative Research in Psychology 3(2): 77-101.

Brouwer, M. 2000. "Entrepreneurship and Uncertainty: Innovation and Competition Among the Many." Small Business Economics 15:149-60.

Camerer, C., and D. Lovallo. 1999. “Overconfidence and Excess Entry: An Experimental Approach.” American Economic Review 89(1): 306-18.

Crawford, C. 1987. "New Product Failure Rates: A Reprise.” Research Management 30(4): $20-24$.

Cox, J., and J. Hassard. 2007. "Ties to the Past in Organization Research: A Comparative Analysis of Retrospective Methods." Organization 14(4): 475-97.

Cui, A. S., and F. Wu. 2016. "Utilizing Customer Knowledge in Innovation: Antecedents and Impact of Customer Involvement on New Product Performance.” Journal of the Academy of Marketing Science 44(4): 516-38.

Damanpour, F. 1996. "Organizational Complexity and Innovation: Developing and Testing Multiple Contingency Models.” Management Science 42(5): 693-716.

Dasgupta, P. 1988. “Trust as a Commodity.” In Trust Making and Breaking Cooperative Relations, edited by D. Gambetta. New York: Basil Blackwell.

Decelle, X. 2004. A Conceptual and Dynamic Approach to Innovation in Tourism. Paris: OECD. 
Dew, N., and S. Sarasvathy. 2009. “Affordable Loss: Behavioral Economic Aspects of the Plunge Decision.” Strategic Entrepreneurship Journal 3(2): 105-26.

Dohmen, T., A. Falk, D. Huffman, U. Sunde, J. Schupp, and G. Wagner. 2005. “Individual Risk Attitudes: New Evidence From a Large, Representative, Experimentally Validated Survey. Bonn: IZA Discussion Paper No. 1730, Institute for the Study of Labor (IZA).

Drucker, P. F. 1985. Innovation and Entrepreneurship: Practice and Principles. New York: Harper Business.

Eisenhardt, K. 1989. Building Theories from Case Study Research. The Academy of Management Review 14(4): 532-50.

Fisher, G., S. Kotha, and A. Lahiri. 2016. "Changing with the Times: An Integrated View of Identity, Legitimacy, and New Venture Life Cycles.” Academy of Management Review 41(3): 383-409.

Fox, C., and A. Tversky. 1995. “Ambiguity Aversion and Comparative Ignorance.“ Quarterly Journal of Economics 110(3): 585-603.

Freel, M. S. 2005. "Perceived Environmental Uncertainty and Innovation in Small Firms." Small Business Economics 25(1): 49-64.

Fu, H., F. Okumus, K. Wu, and M. Ali Köseoglu. 2019. "The entrepreneurship research in hospitality and tourism." International Journal of Hospitality Management 78: 1-12.

GEM (2018). 2017/2018 Global Report. London: GEM.

Gifford, S. 2003. "Risk and uncertainty." In Handbook of Entrepreneurship Research, edited by Z. J. Acs and D B. Audretsch, 37-53. Boston, MA: Springer.

Goodman, L. A. 1961. "Snowball Sampling.” The Annals of Mathematical Statistics 32: 14870. 
Gronum, S., M.L. Verreynne, and T. Kastelle. 2012. "The Role of Networks in Small and Medium-Sized Enterprise Innovation and Firm Performance.” Journal of Small Business Management 50(2): 257-82.

Hall, C., and A. Williams. 2008. Tourism and innovation. London: Routledge.

Heidenreich, S., and P. Spieth. 2013. "Why Innovations Fail: The Case of Passive and Active Innovation Resistance.” International Journal of Innovation Management 17(5): 1-42.

Heidenreich, S., and T. Kraemer. 2015. "Passive Innovation Resistance: The Curse of Innovation? Investigating Consequences for Innovative Consumer Behavior.” Journal of Economic Psychology 51:134-51.

Heiman, A., B. McWilliams, and D. Zilberman. 2001. "Demonstrations and Money-Back Guarantees: Market Mechanisms to Reduce Uncertainty.” Journal of Business Research 54(1): 71-84.

Hoholm, T. and L. Araujo. 2011. "Studying Innovation Processes in Real-Time: The Promises and Challenges of Ethnography.” Industrial Marketing Management 40: 933-39. Ioannides, D., and T. Petersen. 2003. “Tourism 'Non-Entrepreneurship' in Peripheral Destinations: A Case Study of Small and Medium Tourism Enterprises on Bornholm, Denmark.” Tourism Geographies 5(4): 408-35.

Jack, S. 2005. "The Role, Use and Activation of Strong and Weak Network Ties: A Qualitative Analysis.” Journal of Management Studies 42(6): 1233-59.

Jalonen, H. 2012. "The Uncertainty of Innovation: A Systematic Review of the Literature." Journal of Management Research 4(1): 1-53.

Janeway, W. 2012. Doing Capitalism in the Innovation Economy. Cambridge: Cambridge University Press. 
Jawahar, I. M., and G.L. McLaughlin, G. L. 2001. "Toward a Descriptive Stakeholder Theory: An Organizational Life Cycle Approach.” Academy of Management Review 26(3): 397-414.

Johnson, D. 2001. "What is Innovation and Entrepreneurship? Lessons for Larger Organisations.” Industrial and Commercial Training 33(4):135-40.

Jovanovic, B. 1982. "Selection and the Evolution of Industry." Econometrica: Journal of the Econometric Society 50(3): 649-70.

Kahneman, D. 2003. “A Perspective on Judgment and Choice: Mapping Bounded Rationality.” American Psychologist 58(9): 697-720.

Kahneman, D., and A. Tversky. 1979. "Prospect Theory: An Analysis of Decision Under Risk.” Econometrica 47:263-91.

Kanbur, R. 1980. “A Note on Risk Taking: Entrepreneurship and Schumpter.” History of Political Economy 12(4):489-98

Kanter, R. M. 1988. "When a Thousand Flowers Bloom: Structural, Collective, and Social Conditions for Innovation in Organisations.” In Research in Organizational Behavior, edited by L. L. Cumming, 169-211. Greenwich, CT: JAI Press.

Keizer J., J. Vos, and J. Halman. 2005. "Risks in New Product Development: Devising a Reference Tool.” R\&D Management 35(3):297-309.

Keynes, J. M. 1937. “The General Theory of Employment.” The Quarterly Journal of Economics 51(2): 209-23.

Kim, J., and D. Wilemon. 2002.” Strategic Issues in Managing Innovation’s Fuzzy FrontEnd.” European Journal of Innovation Management 5(1): 27-39. 
Kim, Y., and N. Vonortas. 2014. "Managing Risk in the Formative Years: Evidence from Young Enterprises in Europe.” Technovation 34(8): 454-65.

Kleijnen, M., N. Lee, and M. Wetzels. 2009.” An Exploration of Consumer Resistance to Innovation and its Antecedents.” Journal of Economic Psychology 30(3): 344-57.

Knight, F. H. 1921. Risk, Uncertainty and Profit. New York: Hart, Schaffner and Marx.

Lane, D. A., and R.R. Maxfield. 2005. “Ontological Uncertainty and Innovation.” Journal of Evolutionary Economics 15(1): 3-50.

Lang, J., R. Calantone, and D. Gudmudson. 1997. "Small Firm Information Seeking as a Response to Environmental Threats and Opportunities.” Journal of Small Business Management 35(1): 11-23.

Lee, J. S., and S.C. Jang. 2007. “The Systematic-Risk Determinants of the US Airline Industry.” Tourism Management 28(2): 434-42.

Levitt, T. 1965. “Exploit the Product Life Cycle.” Harvard Business Review 43(6): 81-94.

Liesch, P. W., L.S. Welch, and P.J. Buckley. 2011. "Risk and Uncertainty in Internationalisation and International Entrepreneurship Studies.” Management International Review 51:851-73.

Luoma, T., and J. Paasi. 2007. Managing Commercialisation Risks in Innovation Development: Linking Front End and Commercialisation. Proceedings of the XIX ISPIM Annual Conference. Open Innovation: Creating Products and Services through Collaboration. Tours, France (Vol. 18).

March, J. G., and Z. Shapira. 1987. "Managerial Perspectives on Risk and Risk Taking.” Management Science 33(1): 1404-18. 
Marshall, C., and G. Rossman. 2006. "The How of the Study: Building the Research Design.

In Designing Qualitative Research, edited by C. Marshall and G. Rossman, 55-101. Thousand Oaks: Sage Publication.

Masurel, E., and K. Van Montfort, K. 2006. "Life Cycle Characteristics of Small Professional Service Firms.” Journal of Small Business Management 44(3): 461-73.

McKelvie, A., M. Haynie and V. Gustavsson. 2011. "Unpacking the Uncertainty Construct: Implications for Entrepreneurial Action.” Journal of Business Venturing 26(3): 273-92.

Miles, M., and M. Huberman. 1994. Qualitative Data Analysis. Thousands Oaks, CA: Sage.

O’Connor, G., T. Ravichandran, and D. Robeson. 2008. "Risk Management Through

Learning: Management Practices for Radical Innovation Success.” Journal of High

Technology Management Research 19(1): 70-82.

Ogawa, S., and F. Piller. 2006. "Reducing the Risks of New Product Development.” MIT Sloan Management Review 47(2): 65-71.

Olson, P. D. 1985. "Entrepreneurship: Process and Abilities.” American Journal of Small Business 10(1): 25-31.

Oreg, S., and J. Goldenberg. 2015. Resistance to Innovation: Its Sources and Manifestations. Chicago: University of Chicago Press.

Park, S., N. Yaduma, A. Lockwood, and A.M. Williams. 2016. "Demand Fluctuations, Labour Flexibility and Productivity.” Annals of Tourism Research 59:93-112.

Park, Y. 2010. “A Study of Risk Management and Performance Measures on New Product Development.” Asian Journal on Quality 11(1): 39-48.

Perminova, O., M. Gustafsson, K. Wikstrom. 2008. "Defining Uncertainty in Projects-A New Perspective.” International Journal of Project Management 26(1): 73-9. 
Pittaway, L., M. Robertson, K. Munir, D. Denyer, and A. Neely. 2004. "Networking and Innovation: A Systematic Review of The Evidence." International Journal of Management Reviews 5(3-4): 137-68.

Power, S., M.L. Di Domenico, G. Miller. 2019. “Risk Types and Coping Mechanisms for Ethical Tourism Entrepreneurs: A New Conceptual Framework.” Journal of Travel Research 00(0):114.

Rehn, A., and M. Lindahl. 2011. "Muddling Through in Innovation - On Incremental Failure in Developing an Engine.” Journal of Business Research 65(6): 807-13.

Ritchie, B. W. 2004. "Chaos, Crises and Disasters: A Strategic Approach to Crisis Management in the Tourism Industry.” Tourism Management 25:669-83.

Ritchie, J., and L. Spencer. 1994. “Qualitative data analysis for applied policy research. In Analyzing Qualitative Data, edited by A. Bryman and R. Burgees, 173-194. London: Routledge.

Rodriguez, I., A.M. Williams, and M. Brotons. 2017. “The Innovation Journey of New-ToTourism Entrepreneurs.” Current Issues in Tourism 22(8):877-904.

https://doi.org/10.1080/13683500.2017.1334763

Rodriguez, I., A.M. Williams, and H. Andreu. 2019. Customer Resistance to Tourism Innovations: Entrepreneurs' Understanding and Management Strategies. Journal of Travel Research (in press).

Schumpeter, J. 1934. The Theory of Economic Development. Cambridge, MA: Harvard University Press.

Schumpeter, J. 1942. Capitalism, Socialism and Democracy. New York: Harper and Row. 
Shepherd, D., E. Douglas, and M. Shanley. 2000. "New Venture Survival: Ignorance, External Shocks, and Risk Reduction Strategies.” Journal of Business Venturing, 15(5-6): 393-410.

Shepherd, D.A. 2015. "Party on! A call for entrepreneurship research that is more interactive, activity based, cognitively hot, compassionate, and prosocial.” Journal of Business Venturing, 30(4): 489-507.

Shook, C. L., R.L. Priem, and J.E. McGee. 2003. "Venture Creation and the Enterprising Individual: A Review and Synthesis.” Journal of Management 29(3): 379-99.

Simon, M., S.M. Houghton and K. Aquino. 2005. "Cognitive Biases, Risk Perception and Venture Formation: How Individuals Decide to Start Firms.” Journal of Business Venturing 15(2): 113-34.

Skokic, V., P. Lynch. and A. Morrison. 2016. "Hotel entrepreneurship in a turbulent environment." International Journal of Hospitality Management 53: 1-11.

Smith, P. G., and G.M. Merritt. 2002. Proactive Risk Management: Controlling Uncertainty in Product Development. New York: Productivity Press.

Souder, W. and K. Moenaert. 1992. "Integrating Marketing and R\&D Project Personnel Within Innovation Projects: An Information Uncertainty Model. Journal of Management Studies 29(4): 485-512.

Stenbacka, C. 2001. "Qualitative Research Requires Quality Concepts of its Own.” Management Decision 39(7): 551-56.

Stevens, G.A., and J. Burley. 1997. “3,000 Raw Ideas = 1 Commercial Success!” Research Technology Management 40(3): 16-27. 
Stewart Jr, W. H., W.E. Watson, J.C. Carland, and J.W. Carland. 1999. “A Proclivity for Entrepreneurship: A Comparison of Entrepreneurs, Small Business Owners, and Corporate Managers.” Journal of Business Venturing, 14(2): 189-214.

Stinchcombe, A. L. 1965. “Organizations and Social Structure.” Handbook of Organizations 44(2): 142-93.

Sthyre, A. 2004. "Rethinking Knowledge: A Bergsonian Critique of the Notion of Tacit Knowledge." British Journal of Management 15(2): 177-88.

Storey, D., and N. Sykes. 1996. "Uncertainty, Innovation and Management.” In Small Business and Entrepreneurship, edited by P. Burns and J. Dewhurst. London: Macmillan. Teece, D., M. Peteraf, and S. Leih. 2016. "Dynamic Capabilities and Organizational Agility: Risk, Uncertainty, and Strategy in the Innovation Economy." California Management Review 58(4): 13-35.

Thomas, R., G. Shaw and S.J. Page. 2011. "Understanding Small Firms in Tourism: A Perspective on Research Trends and Challenges.” Tourism Management 32(5): 963-76. Thomke, S. and D. Reinertsen. 1998. “Agile Product Development: Managing Development Flexibility in Uncertain Environments.” California Management Review 41(1): 8-30.

Van Gelderen, M., M. Frese, and R. Thurik. 2000. "Strategies, Uncertainty and Performance of Small Business Startups.” Small Business Economics 15:165-81.

Venkataraman, S. 1997. “The Distinctive Domain of Entrepreneurship Research.” Advances in Entrepreneurship, Firm Emergence and Growth 3(1): 119-38.

Verreynne, M,-L., A.M. Williams, B. Ritchie, S. Gorum, and K.S. Betts. 2019. "Innovation Diversity and Uncertainty in Small and Medium Sized Tourism Firms.” Tourism Management 72:257-269. 
Wärneryd, K.E. 1988. “The Psychology of Innovative Entrepreneurship. In Handbook of Economic Psychology, edited by W.F. vanRaaij, G.M. van Veldhoven, and K.E. Wärneryd, 404-47. Dordrecht, Netherlands: Kluwer.

Winborg, J. 2009. "Use of Financial Bootstrapping in New Businesses: A Question of Last Resort?” Venture Capital 11(1): 71-83.

Williams, A. M., and V. Baláž. 2013. “Tourism, Risk Tolerance and Competence: Travel Organization and Tourism Hazards.” Tourism Management 35:209-21.

Williams A. M., and V. Baláž. 2014. "Tourism, Risk and Uncertainty: Theoretical Reflections.” Journal of Travel Research 54(3): 271-87.

York, J. G., and S. Venkataraman. 2010. “The entrepreneur-environment nexus: Uncertainty, Innovation, and Allocation.” Journal of Business Venturing 25(5):449-63. 